In $\mathbf{1 7 8}$ myomectomies performed during the same period there was one death, also a mortality of 0.6 per cent.

On all grounds, therefore, it would appear that operative treatment is much better than $X$ ray or radium treatment in dealing with uterine fibroids.

\section{A SYMPOSIUM}

ON

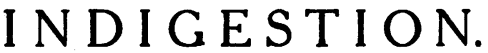

Being Remarks of the Opening Speakers at a Recent Discussion on this subject at the Hunterian Society.

II. THE MENTAL ASPECT.

BY

H. CRICHTON-MILLER, M.A., M.D. Edin., HON. DIRECTOR, TAVISTOCK CLINIC FOR FUNCTIONAL NERVE CASES.

THE first and most important emotion connected with dyspepsia is fear. We all know the degree to which fear can exaggerate discomfort into pain and pain into agony. This process is most liable to occur, of course, in hysterics, but those of us who claim to be perfectly balanced as far as our emotional lives go are not immune from such a process. It is probable that the first bogy which arises in connection with dyspepsia is cancer. The idea that a chronic or recurring gastric pain may indicate the early stages of a malignant growth is one that many patients entertain. Frequently they are ashamed of it, and it is only the alert and intuitive physician that allays it. Many dyspeptics who suffer from atonic distension believe that the cardiac oppression is due to actual disease of the heart. This fear is much less challenging than that of cancer, and, therefore, patients are much less disposed to be secretive about it.

\section{INSOMNIA.}

Then there is insomnia. I think few of us realise how much insomnia is caused by dyspepsia. A patient wakes up regularly at a given hour-it may be three or it may be six-and cannot get to sleep again for a long time. We ask him if he has any indigestion, and he denies it. But if we ask him to observe himself closely he is likely to discover that though he hàs no pain or even appreciable discomfort, there is some gas to be released every time. The treatment must, of course, be directed to his digestion and not to his sleep function. This connexion is important in a double way. In the first place, lying awake is a bad thing for the mental life of the average individual. It gives opportunity for much thought that is unduly emotional and inadequately logical. In the second place, it starts the vicious circles of insomnia which is of all the vicious circles of pathology one of the worst. Most people' fear insomnia much more than they fear gastralgia. When dyspepsia remains latent, but produces insomnia as an apparently inexplicable phenomenon, it creates the fear of insomnia which tends to produce more insomnia in a more marked way than the fear of indigestion produces mote indigestion. The reason why sleep is broken so slight an indigestion is simple enough when recall that sleep is primarily a vascular phenomenon. As far as we know, cerebral ischæmia 'is the most prominent physiological change that accompanies sleep. Even though it be not the causa causans of sleep, we can certainly say theft it is an essential condition of normal sleep. In the redistribution of the blood which permits of the brain being devascularised, the most important item is the relative proportion of blood that passes through the descending aorta. Any form $\overrightarrow{\theta f}$ resistance which tends to diminish that proportion must militate against cerebral ischæmia. Hencae the weight of a laden stomach or the pressure of a distended stomach both make for an active cerebs circulation, which in turn causes wakefulness. The differences, however, are important. The heavily loaded stomach obstructs the descending aorta chiefly in a supine position ; the distended stomaan produces its effect in any position ; while the formor interferes with early sleep, the latter more usually allows the patient to sleep for some hours beforge the pressure reaches its maximum. In this conne tion I should like to utter a protest against the routine remedy of most nurses-I mean the glass of hot milk. I consider this a most insidious evf, because by reason of the fact that it is hot and liquid it frequently sends the patient to sleeser. But very frequently I believe the fermentatien which ensues actually increases insomnia.

One further aspect of fear in connection wish dyspepsia I should like to refer to. It is hæmagemesis. Few of us probably realise the profound emotional shock induced by the first hæmatemesis, with all its gruesome suddenness and novelty. If we did realise it, we would understand that victim will for the future inevitably associate every gastric discomfort with the possibility of recurrence.

\section{SuggestibILITY.}

Now fear in these various forms has two results. The first is to promote dyspepsia, and the second to increase suggestibility. Let us take the latter first. As a class dyspeptics are suggestible. He know that from the proportion of the worles publicity which they pay for. Suggestibility is the handmaid of fear. It is because dyspepsia -\$o frequently brings in its train some haunting fest, such as has been described, that the dyspeptic tends to become less rational and more suggestible in regard to his health. Therefore the quack medicime merchant, the faith-healer, the Christian Scientiegt, the diet crank, qualified or unqualified, the spas with noisome waters-all these have a definite therapeutic advantage as far as immediate resutps are concerned. For permanent cures there is sonething to be said in favour of the sound physician. And here it may be pointed out that the sugges bility of the dyspeptic constitutes a snare to many an otherwise sound physician. The dyspeptic likesa 
diet sheet. He likes to be told that he may eat crab, but on no account lobster. At least, the more suggestible dyspeptic likes it. And there are some physicians who enjoy telling him that he can eat whiting but not plaice. I believe this procedure to be fundamentally mistaken. Dyspepsia is not diabetes, nor yet arterio-sclerosis. It is right and proper that in such diseases we should authoritatively set down what is allowed and what is forbidden. Our information comes from the laboratory, and the patient has little or no means of helping us. But when it comes to dyspepsia we have not only laboratory findings, but the patient's experience to guide us, and we should welcome that experience as an indication of his idiosyncracies. Instead of that, some of us are tempted to show our profound knowledge of dietetics by forbidding an article that the patient had always imagined agreed with him particularly well. If he be sufficiently suggestible he will go home and tell his wife how clever we are, and never touch the article in question for months, and then in a moment of self-assertion indulge in it and suffer for the first time. I believe that sound dietetics demand that we should carefully study the patient's report of what agrees and what does not agree with him, and stimulate him to careful observation in a detached spirit. We frequently trade on the fear of the dyspeptic, and make him more apprehensive than ever in regard to diet.

\section{The Fear-Process.}

I have said that fear promotes dyspepsia. Not only does it do so in the way I have shown, but also by the ordinary mechanism of the sympathetic nervous system. If we tell a victim of mild hyperchlorhydria that unless his symptoms soon clear up we shall have to operate on a presumptive duodenal ulcer, we establish a fear-process. That fearprocess works just like any other fear-process, be it the fear of bankruptcy or the fear of shipwreck. It stimulates the adrenals, and their secretion in turn stimulates the thyroid; all unstriped muscle becomes hypertonic ; all the arteries are constricted. As a result we have a more or less violent interference with two factors of digestion : $(a)$ peristalsis, and $(b)$ the vascularity of the mucosa. The proper cure for this condition is not atropine, but analysis. The fear of dyspepsia may have increased the dyspepsia. That is generally the physician's fault, and he had better retrace his steps. Or fear may have produced dyspepsia. In that case the physician had better find out what the fear is. Only those who have experience of mental analysis realise the pathogenic importance of the fears of the man who begins by saying that he has no fear. When we satisfy ourselves so easily that the psychological factor may be ignored, we are likely to land ourselves in the most usual and most baffling of all therapeutic quagmires--that of treating with physical remedies a condition that is based on emotional causes.

[The opening remarks on the Medical Aspect of the question will be published in our next number.-ED.]

\section{INFECTIVE OSTEOMYELITIS IN CHILDHOOD.}

\author{
BY \\ H. A. T. FAIRBANK, D.S.O., M.S. LoNd., \\ F.R.C.S. ENG., \\ SENIOR SURGEON, HOSPITAL FOR SICK CHILDREN; SENIOR \\ ORTHOP FDIC SCRGEON, KING'S COLLEGE HOSPITAI.
}

BY this title I mean an osteomyelitis, acute, subacute, or chronic, due to one cf the pyogenic organisms, excluding those due to tubercle and syphilis. From the pathological point of view osteomyelitis may res!lt in rarefaction, in sclerosis or necrosis. The particular result that we see depends on the virulence of the affecting organism. An acute infection is more likely to lead to some rarefaction, and particularly to necrosis ; a chronic one to rarefaction or sclerosis. These cases of infection cf bone used to be classified into myelitis, osteitis, and periostitis, but, speaking generally, every inflammation of bone which has lasted for more than a day or two involves all these structures, periosteum, bone and marrow, wherever it begins. The trouble usually starts in the scft bone at the end of the diaphysis as an osteitis, affecting the cancellous tissue at the end of the bone, and very soon getting into the medulla and causing a myelitis. Periostitis does occur as the essential part of an inflammatory lesion, but only exceptionally. The periosteum is only affected secondarily in the ordinary cases which we see and which we are considering to-day-i.e., the ordinary acute inflammation of bone in children. We occasionally see a lesion where the infection is very defir itely limited to one side of the bone, and, therefore, looks rather as if it began as a periostitis, but the possibility of acute periostitis occurring by infection through the blood stream can be disregarded. The causative orgarisms are various, the commonest undoubtedly being the Staphylococcus aureus. Fraser, of Edinburgh, some time ago noted the infective organisms in 200 cases : in 61 per cent. he fourd Staphylococcus aureus, and 29 per cent. pneumo. coccus, so that these two groups representer 90 per cent. of the cases. Six per cent. grew streptococci, and 3 per cent. the Staphylococcus albus. Occasionally unexpected organisms occur as the cause of this condition. For instance, Dr. Nabarro tells me there have recently been two cases in this hospital where Bacillus paratyphosus B had caused an osteomyelitis without any antecedent or present infection of the bowel ; the bone lesion seems to have been the only lesion where the organism was found. One of these cases proved fatal. Typhoid osteomyelitis has, of course, been recognised for many years, though it is not seen much nowadays since typhoid ferer has become so much less common. 